\title{
Waste not, want not
}

\author{
Earth's resources may not be running out, but the planet's capacity to cope with the resulting waste products \\ is limited. Resource geology can no longer be the preserve of the economic, mining or petroleum geologist; \\ sustainably providing for the world's population requires a broader skillset.
}

A lthough the Earth can be considered a finite system, the human population it supports is increasing. The United Nations estimates that roughly 83 million people will be added every year and that Earth's population will be nearly 10 billion by 2050 ( ref. $^{1}$ ). The proliferation of conferences in 2018 on natural resources and society - such as the recent Resources for Future Generations meeting (https:// go.nature.com/2uNxJSP); the Mineral resources at the frontier meeting (https:// go.nature.com/2uwHJAs); and our own Nature conference, Materials and Metals for Sustainable Development, upcoming in September in Norway (https://go.nature. com/2NVZi5b) - shows that geoscientists are increasingly thinking about how to resource this expanding population.

In developed nations, the average person consumes 16 tons of resources (for example, minerals, ores, fossil fuels and biomass) each year. This can reach up to 40 tons, ten times greater than the average resource consumption per person in India ${ }^{2}$. It is reasonable to think that as countries grow and prosper, they will increase their per capita consumption. Indeed, with every $1 \%$ increase in gross domestic product there is a $1.9 \%$ increase in the metal ore extracted to satisfy the country's demand ${ }^{3}$. Globally, this has led to a tripling of ore extraction between 1970 and 2010. There is a growing sense that we must decouple economic growth from the use of natural resources: to learn to do more with less.

Consumption is often thought of as a destructive, linear process in which resources are extracted, made into a product, used, and disposed of. Such a linear model seemingly leads to two problems: ever-decreasing resource inputs and everincreasing waste products (for example, greenhouse gases into the atmosphere, heavy metals into water bodies, and products into landfill).

Although Earth is a finite system, it is unlikely that running out of raw materials is going to be the limiting factor. Of course, it is possible that resources such as fossil fuels and critical metals could be used to their ultimate elimination. However, global resources are massive and human innovation tends to find alternatives before they run out. Raw materials may become economically unviable, costing more to extract than they are worth, but ultimate resource exhaustion is unlikely. Therefore, it is the waste products and environmental consequences of resource exploitation that may prove to be the limiting factors. For example, technologies such as hydraulic fracturing have facilitated the utilization of previously unavailable hydrocarbons. Technology has extended the fossil fuel age but, with a warming climate and increasingly acidified and deoxygenated oceans ${ }^{4}$, greener energy solutions must be found and used (Fig. 1) and innovations in waste management must be made.

However, not all consumption has to be destructive. In a circular economy, resources are kept in use for as long as possible and emission and energy leakage are slowed. This requires long-lasting design including the ability to: repair, reuse, refurbish and in the end - recycle component parts or return them to the biosphere. In this model, by reducing demand for new raw material extraction and processing, waste is decreased. But, despite how much waste we eliminate, with a growing population and new, as of yet unimagined technologies to resource, we will inevitably need more, and different, raw materials.

In a sustainable world, the role of geologists is crucial for both exploring new resource frontiers and understanding the total impact of their exploitation. No longer are resources only within the scope of economic and petroleum geology. It will be - or maybe already is - incumbent on those trained in geoscience to use the multidisciplinary systems approach to understanding the Earth to collaborate in order to understand what resources are available, what the consequences of their extraction and utilization will be, and how we can limit negative effects. Only with such an interdisciplinary approach can pragmatic, scientifically based decisions be made to sustainably manage the Earth's natural resources to support our growing population.

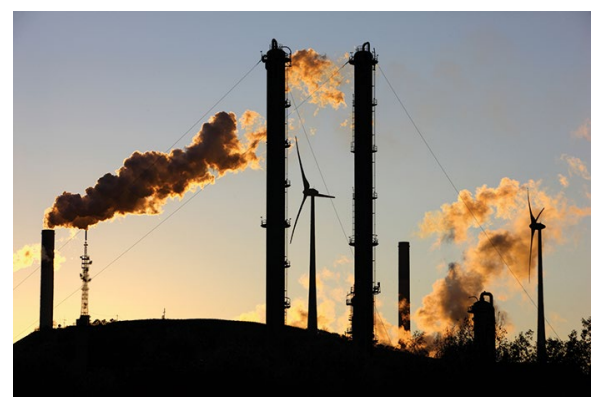

Fig. 1 | A changing energy landscape. The coal-fired Scholven Power Station, Germany, was commissioned in the 1940s, burning coal to generate power but also releasing waste greenhouse gases to the atmosphere. The encroaching wind turbines - requiring steel, copper, aluminium, rare earth elements, zinc and molybdenum - generate renewable energy without the associated waste but still require innovation in design, decommissioning and recycling to limit the total impact of their manufacture and use. Credit: Jochen Tack / Alamy Stock Photo

Conversations about resources often focus on the need for a sustainable future for the next generation. However, with decreasing fertility rates, we are an ageing population - the number of people aged over 60 is set to double by 2050 and triple by 2100 ( ref. $^{1}$ ). So, while it is noble to think that we are problem solving for our grandchildren, we should remember that many of us will be around to see the successes and failures of our current endeavours. For now, we look forward to seeing the fruits of the discussions started at conferences this year and the efforts already in progress to tackle these issues.

Published online: 31 July 2018

https://doi.org/10.1038/s41561-018-0211-8

\footnotetext{
References

1. World Population Prospects: The 2017 Revision, Key Findings and Advance Tables (UN, 2017).

2. Fischer-Kowalski, M. et al. Decoupling Natural Resource Use and Environmental Impacts from Economic Growth (UNEP, 2011).

3. Zheng, X. et al. Nat. Geosci. 11, 269-273 (2018).

4. Oschlies, A. et al. Nat. Geosci. 11, 467-473 (2018)
} 